\title{
From prayers to surgeries - journey of medical tourism
}

\author{
Dr. Anu Rai ${ }^{1}$

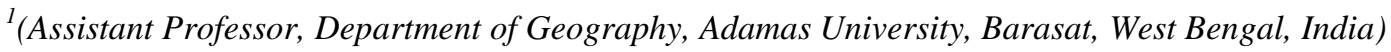

\begin{abstract}
An act of travelling far from the place of residence to obtain healthcare benefits is not a new phenomenon; rather it is an ancient social practice where people for thousands of years have travelled to seek cures through some unique and authentic health solutions, available only certain specific locations of the world. This article is an attempt to identify the emerging trend of medical tourism in its contemporary form since ancient period. It also highlights the changing attributes of medical tourism while passing through different societies under different cultural system.
\end{abstract}

Keywords - healthcare tourism, history, religious therapeutics, regional imbalance, medical tourism, market forces

\section{INTRODUCTION}

As a spatial phenomenon, health care tourism is an ancient response against the interplay among places, spaces, objects, practices and experiences that simply aims at certain health benefits of seekers. Various places from thousands of years have attracted travellers for the sake of health. Most ancient civilizations recognized the therapeutic effects of spiritual practices or faith healing. Sacred sites in Greece, Egypt, India, Italy and Persia for many thousand years were sites of healing. For at least 2000 years ago, Romans were aware about the health benefits of bathing in mineral springs. Certain environments were considered of having health benefits in Britain and Japan. Ayurveda and Traditional Chinese Medicine (TCM) have existed for millennia, not available elsewhere. Islamic and Indian hospitals of medieval period were major centers of attraction for many patients irrespective to their race, caste and socio - cultural background. In $20^{\text {th }}$ Century, USA and Europe have developed its medical technology and emerged as famous destination for elite patients. Last decades have witnessed emergence of many global healthcare centers, hosting patients across the globe that are travelling in search of better healthcare opportunities, not accessible at their place of residence.

\section{HEALTH CARE TOURISM - A BROADER PERSPECTIVE}

Healthcare Tourism is an ancient social practice, features movement of people to seek cures or certain health benefits through prayers, relaxation, exercise or visits to spas, specific to a particular destination and its natural and cultural resources (Hunter, 2007) ${ }^{[1]}$. However, everything else today health tourism is an area in which individuals have taking advantages of globalization. Specialization has transformed it into niche markets include specific medical interventions (Tata, 2009) ${ }^{[2]}$. In broader sense depending on the nature of resources used both physical and cultural, different objects and practices involved and driven by various circumstances, an act of health tourism can be characterised under following themes:

\subsection{Religious therapeutics - roots in spiritual healing}

Religion and medicine are two distinct fields of human endeavour, but the need for well - being of body, mind and sprits marks the indispensable ground of religious and healthcare efforts (Fields, 2001) ${ }^{[3]}$. Most ancient civilization recognized the therapeutic effects of spiritual or faith healing that is believed to have occurred supernaturally, as a result of specific religious practices and principles such as prayers, meditation or other forms, rather than the use of medicines or other healing practices (Gautam, 2008) ${ }^{[4]}$. Many Gods of Ancient Egypt were prominent as healers and their sanctuaries were centre of attractions for hundreds. BES or BESA from Central Africa was considered as a deity of pleasure, mirth, laughter, music and dancing, protector of children and their mothers. He was worshipped at the Serapeum at Memphis, where divination by incubation for healing was practiced. NEITH was also one of the healing deities, her temple at Saïs being celebrated as a healing sanctuary and having attached to it a medical school. Her annual festival of Lamps at Saïs was famous throughout the Egyptian history. During Graeco - Roman epoch THOTH and his sanctuary in Heamopolis was probably the greatest healing temple of ancient Egypt had attracted many health seekers. THOTH was popular as a protector against evil and especially against illness, delivering man from his perils. The essentials of medicine consisted in the rites and formulas by which malicious beings that caused disease were exorcised and expelled from the bodies of victims and hence were magical. As a magician, THOTH was considered to be the powerful patron of physicians (Jayne, 1925) ${ }^{[5]}$. 
The Hindu sub traditions are in general concerned with well being of persons in their spiritual dimensions. It has a more holistic view of the human being as a unity; with psychophysical and spiritual dimensions as a result there is much greater affinity between religion and healthcare (Fields, 2001) ${ }^{[3]}$. Pilgrim Centres of Ancient Indian Civilization were widely famous for the ATHARVAN treatment, was always magic veneered with religion - a hymn with an oblation or prayers addressed to the Gods and Goddess, to the disease or demon of disease or to the remedy (Jayne, 1925) ${ }^{[5]}$. Ayurveda, a widely practised traditional healthcare system till date is seen as a system of treatment given directly by the God of Life and Medicine DHANVANTARI, an incarnation of Lord Vishnu (Gopi, 2014) ${ }^{[6]}$. According to legends when the Devas and Asuras were churning the primeval ocean, Lord DHANWANTARI rose from the Ocean of Milk with the pot of Amrit in one hand. He was Lord Vishnu incarnate and had the divine Sri Chakra, Sankh, Jaluka (blood sucking leech that cures one of impure blood) and medicinal herbs. He is also a great surgeon who taught Ayurvedic Surgery to Susruta, the father of Ayurvedic Surgery. In Kerala near Kotakkalat Pulamantol village, in Trishura's Perungva, in a village called Nelluvayi, $20 \mathrm{kms}$ from Guruvayur and Trissur, and in the outskirts of Calicut city, ancient temples of Lord DHANWANTARI are still present. It is believed that these temples are important since the period of Ashta Vaidya as people come here from far off places to offer their prayers to Lord, to cure them of their ailing diseases, or to be blessed with a healthy life ahead. In Karnataka there is a temple of Dhanvantari Mahavishnu at Yelaguppa near Honnavar in Uttara Kannada District dates back to 1000 years ago. In fact 'religion' and 'health' are indispensable features of Hinduism since its inception. Several seals and sealing unearthed at Harappa and Mohenjodaro, dates back to 2300 - 1700 B.C.E. portray a figure of shamans or medicine men, who heals by means of magical rituals includes such elements as ecstatic dance, magical flight, the use of potent herbs and amulets, the recitation of incantations and exorcisms (Zysk, 1991) ${ }^{[7]}$. Early epigraphical records depict the healing houses and its association with Vaishnava temple (Bhagavatpadayatana) in Gujarat. This temple was famous for both local and outsiders (Chakravorty and Ray, 2011) ${ }^{[8]}$. An important Eleventh Century (1069 A.D.) Tamil inscription from the Vishnu temple of Venkatesa Perumal at Tirumukkudal in Tamilnadu also depicts about the hospital attached to the temple, constructed during second half of the 11th century at Chingleput region of Tamilnadu (Zysk, 1991) ${ }^{[7]}$. There is an instance of medical facilities available at Shaiva religious complex within Pala realm. An arogyasala or healing house dated to the reign of Pala rulers Nayapala (1027 - 43 AD) within Shiva temple was made available for all including religious community and the people from near and far in general (Chakravorty and Ray, 2011) ${ }^{[8]}$. The association of healing houses with Buddhist monastery is also obvious. An inscription from Nagarjunikonda in ancient Vijayapuri in Andhra Pradesh, a celebrated city and Buddhist Centre dating from the $3^{\text {rd }}$ Century C.E. depicts that a healing house for the care of those suffering and recovering from fever was a major part of this principal Buddhist monastery. According to $\mathrm{Fa}-\mathrm{Hsien}$, arogyavihara or healing houses for poor, destitute and sick of Buddhist monastery were present at Pataliputra during $5^{\text {th }}$ century C.E. Mortars and pestles excavated from the Monastery at Sarnath, near Banaras exhibit the use of the monastery to nurse and to provide cure to the sick in the 8th and 9th centuries C.E. (Zysk, 1991) ${ }^{[7]}$. Spiritual healing is also highly recognized in Lord Mahaveera led Jainism in Eastern India some 2600 years ago.

It is believed that Ancient Greeks civilization and the Shrine of ASKLEPIOS, the God of Medicine in a small valley in Peloponnesus at Epidaurus were the first to lay a foundation for a comprehensive health care tourism network since 12 th century B.C. However, Epidaurus entered its greatest period in the $4^{\text {th }}$ century BC, when the temple of Apollo Maneates and the great monuments of the Hieron were built. The Hieron includes the Temple of ASCLEPIOS, the THOLAS, and the ENKOIMETERION where the sick awaited their cures, the Baths of Asklepios. The emergence of modern medicine in a sanctuary originally reputed for the psychology based miraculous healing of supposedly incurable patients. As reflected in numerous records displayed in Greeks museums, the physicians of Asklepieion were wise and careful; they relate the famous seventy miracles of Asklepios and other well organized medical procedures to treat a variety of diseases in a natural way. Famous as an important healing centre, the Asklepieion of Epidaurus used to gather diseased people from all over Greece. Although most of them come to get miraculous cures, they usually had to stay and undergo some treatment. They also used to take natural baths, to have a rest before going back to their place of origin, to thank God Asklepios with offerings and participate in the games that would take place every four year. As a healing deity AMPHIARAOS and his dream - oracle at Oropos was famous at the end of fifth century B.C. where healing was effected through dreams. A holy festival which was largely attended was held at the sanctuary every forth years. ORPHEUS was a celebrated soothsayer and believed to be the chief exponent who recognized the influence of music on certain diseases. He used to exercise healing powers by appeasing the wrath of the Gods through incantations, conjurations and magic formulas. He was considered as divine physician and his famous oracle was at Lesbos. Health seekers from far and near consulted the most ancient shrine of Zeus and the most venerable oracle in Greece at Dodona in Epeiros. The NYMPHS, DRYADE, HAMADRYADS, NEREIDS and similar mythic personages were nature - sprits of the hills, forests, springs and caves with healing functions. Some were worshipped under a collective name. In the village of Herakleia, at a spring flowing into the 
Kytheros River, there was a sanctuary to a group of nymphs who presided over it, collectively termed as IONIDES. It was believed that to bathe in the spring was cure for all kinds of sicknesses and pains. In the Triphylia district of Elis was a warm Sulphur spring issuing from a cave on the banks of the Anigros River, over which ruled a bank of nymphs called the ANIGRIADES. This spring was a cure for all skin diseases while the worship consisted of prayers, vows, bathing and the use of rational remedies. Similarly inscriptions related to Ancient Roman Civilization also depicts about such movement of people for the sake of healthcare under certain religious belief. BONA DEA, the symbol of health and life was a prophetic deity with an oracle and practised healing. Her chief temple in Rome, on the slope of the Aventine beneath a large rock, was a sort of herbarium, stored with medicinal herbs and sacred serpents were kept there. Women used to conduct all cultic and ceremonies cared for the temples, and only women took part. However the cures were not limited to the female sex. FAUNUS was another famous deity of healing among Romans. His most celebrated sanctuary was a sacred groove at Tibur (Jayne, 1925) ${ }^{[5]}$.

\subsection{Exploiting natural resources - means of healing}

Certain natural environments and its exploitation for medicinal benefits is another type of ancient health tourism practices prevailing in ancient societies. Exploitation of natural phenomena such as mineral springs, seawater and flowing water for medical treatment are simply a continuation of ancient tradition that dates back to thousand years. Waters are recognized as sacred and are frequently mentioned in the Vedic literature for their healing powers. Many of waters and streams of Greece, especially the rivers Acheloos and Kephisos were spiritualized and had remarkable curative virtues. Literature depicts that all healing sanctuaries were abundantly supplied with water, and although some of these waters appear to have had definite medicinal properties, they were for the most part magical. In ancient Babylonian culture it is believed that EA representing the healing qualities of springs and waters was the supreme God of healing and was the last resort of the sick and suffering (Jayne, 1925) ${ }^{[5]}$.

Ancient Romans were also aware about the advantages of hot water bath or mineral spring bath. In fact bathing in Rome was communal activity since ancient time. They believed that good health come from bathing, eating, massage and exercise that later led to spa culture. 'Thermae', the large imperial bath complexes developed by ancient Romans were not only healthcare facilities but became commercial and social networking centres for rich and elite. As Romans used hot thermal waters to relieve their sufferings from rheumatism, arthritis and overindulgence in food and drink, they also developed 'thermae' in their colonies taking advantage of hot springs occurred in Europe. Some famous healing centres of Roman culture are

(1) Vichy, France: In 52 B.C., on returning from their defeat at the Battle of Gergovia by the Gallic legions of Vercingetorix, the Romans established a township at their crossing on the Flumen Elaver (Allier). During the first two centuries AD, Vichy was very prosperous because of the therapeutic values of these thermal springs acknowledged by Romans. By the end of the $16^{\text {th }}$ Century, the mineral baths of Vichy had obtained a reputation for having quasi - miraculous curing powers and attracted patients from noble and wealthy classes. The marquise de Sévigné, was a patient in 1676 and 1677, In 1761 and 1762, Adélaïde and Victoire of France, the daughters of Louis XV, came to Vichy who later developed the bathing facilities at Vichy. In 1799, Laetitia Bonaparte, mother of Napoleon, came to be cured with her son Louis. Under Charles X, the great increase in patients wishing to be healed at the springs led to an expansion of the hydrotherapeutic facilities at Vichy (Wikipedia, 2017) ${ }^{[9]}$.

(2) Bath, Somerset: Archaeological evidence shows that the site of the Roman baths' main spring was treated as a shrine by the Britons and was dedicated to the Goddess Sulis. The temple was constructed in $60-70$ A.D. and a bathing complex was built up over the next 300 years. From outstanding architecture to unique social history and continuing culture, the hot springs have played central role in every stage of the development of the Bath city. Since 2006, with the opening of Thermae Bath Spa, the city has attempted to recapture its historical position in the United Kingdom (Wikipedia, 2017) ${ }^{[10]}$.

(3) Aachen, Germany: Aachen is a spa town in North - Rhine Westphalia, Germany at the foot of the Eifel and Ardennes plateaus. It is believed that approximately 5000 years ago its warm sulphur springs had been attracted human inhabitation where they worshipped Grannus, God of Light and Healing. Further at the start of the $1^{\text {st }}$ century Romans were first to channel the hot springs into a spa at Büchel. Since then it became major centre of healing for many (Wikipedia, 2017) ${ }^{[11]}$.

(4) Wiesbaden, Germany: Wiesbaden is one of the oldest spa towns in Europe. It has long been famous for its thermal springs and spa. Use of thermal spring was first documented by the Romans; however the business of spring bathing became an important business at the end of the Middle age (Wikipedia, 2017) ${ }^{[12]}$. 
Among others Buxton in England and Baden in the Austrian State of Lower Austria, mineral springs on the volcanic islands of Lipari are also famous as healing centres since ancient Roman culture. In medieval Japan, hot mineral springs called 'Onsen' were healing destinations throughout the nation due to their healing properties. An 'onsen' is a term for hot springs in the Japanese language, though the term also indicates the bathing facilities and inns around hot springs. In Japan, it is said that Onsen have various medical benefits and a good soak in an onsen heals aches, pains and diseases. Such practices has given onsen a central role in Balneotherapy often known as Onsen Therapy, conducted to maintain health, normalize dysfunctions and prevent illness. Traditionally these onsen were used as healing centres and played crucial role in directing medical travellers in Japan. Some famous Japanese Onsen are -

(1) Arima Onsen, Kita - Ku - Kobe: Arima onsen is one of the oldest hot springs. Many documents since the $8^{\text {th }}$ century A.D. mention this onsen. Gyoki, a Buddhist monk visited here in $7^{\text {th }}$ century who later popularized the healing characteristics of this onsen. In the $16^{\text {th }}$ century Hideyoshi Toyotomi, who visited this onsen several times was major contributor of its development (Seki and Brooke, 2007) ${ }^{[13]}$.

(2) Dōgo Onsen, Shikoku: With a history stretching back to over 1000 years, the name of Dōgo Onsen were mentioned in the Man'yōshū, the oldest existing collection of Japanese poetry compiled sometime after 759 A.D. (Seki and Brooke, 2007) ${ }^{[13]}$.

(3) Beppu Onsen, Beppu: The second largest hot spring after Yellowstone National Park, Beppu Onsen is famous for its richness of physical and cultural resources. Japanese believed that once in the age of Gods, Sukunabikona and Ōkunimushi (Japanese divinity) visited Ehime Prefecture. Sukunabikona fainted from illness, Ōkunimushi then placed a long pipe at the bottom of the sea all the way through from Dōgo Onsen to Beppu for him to save. It is also reported that in Kamakura period Ōtomo Yoriyasu established sanatoria in Beppu to cure wounded in the war against the Mongolian Army (Wikipedia, 2017) ${ }^{[14]}$.

(4) Yunogo Onsen, Mimasaka: The waters of the Yunogo hot springs are a mixture of sodium chloride and calcium chloride, said to have healing effects on those suffering from chronic digestive, disorder, nerve pain, rheumatism, arthralgia, chronic feminine problems, and skin problems. History depicts that Yunogo Onsen is known as Sagi -no - Yu or Hot Water of the Heron because 1200 years ago a Buddhist high priest named En - nin - Houshi discovered that an injured heron bathing its wounded leg in the waters of a hot springs. This is how the special healing powers of these waters were discovered and they now have evolved into a spot where people come to relax and enjoy the waters (Wikipedia, 2017) ${ }^{[15]}$.

(5) Kona Besso, Izu - Nagaoka: Kona Onsen was founded 1300 years ago, since then has attracted big - city dwellers to relax from day - to - day striving (Seki and Brooke, 2007) ${ }^{[13]}$.

(6) Houshi Awazu Onsen, Komatsu: Houshi is a venerable sanctuary for healing, established in 718 A.D. by the Buddhist priest Garyo Houshi, ordered by a ministering elder to build a therapeutic retreat near the mineral springs of Awazu. He was suggested to provide a wellness setting for many who suffered from the disease of the day. Till date Houshi is one of the preferred destinations for medical travellers in Japan (Seki and Brooke, 2007) ${ }^{[13]}$.

(7) Nishimuraya Honkan, Hyogo: Soothing waters were discovered here nearly 1400 years ago by white storks of the Orient. Japanese believed that for 1000 days a priest prayed and healing waters sprang forth from the rocks of Mandara - Yu, today one of Kinosaki's public hot spring bath (Seki and Brooke, 2007) ${ }^{[13]}$.

(8) Bankyu Ryokan, Tochigi: Being one of the oldest ryokan in the area, Bankyu is one of the popular tourist destinations of Yunishigawa village of Japan. It was home to the Toshugu Shrine, the elaborate resting place of Ieyasu Tokugawa, Japan's most famous shogun and has been considered sacred for more than 1200 years (Seki and Brooke, 2007) ${ }^{[13]}$.

Among others, Akayu in Yamagata is historically famous onsen that is believed to have medicinal properties. Asamushi Onsen is the traditional hot spring site in Aamori city in Japan. It was discovered by Ennin in 876 A.D. and later popularised by Hōnen (Wikipedia, 2017) ${ }^{[16]}$. The Post Renaissance Period witnessed the growth in popularity of sea bathing developed from the perceived health benefits of the ancient practice of mineral springs bathes and holy river water bathes such as those at spa in Belgium, Bath in England, Aachen in Germany, Arima in Japan, holy soak in Indus and Ganges in India etc. Seawater was similarly believed to have medicinal benefits, highly recognised after the works of Dr. Charles Russel in 'The Uses of Sea Water' (1753) and William Buchen's 'Domestic Medicine' (1796). Sea bathing in combination with the drinking of seawater 
became fashionable as the cure for various diseases in the $18^{\text {th }}$ century. Several marine hospitals have opened in parts of France and England. However, Sea bathing for pleasure began with the Scarborough. Doctors in the early 19th century and later started Brighton as a seaside resort. Bathing in and drinking seawater as a cure for Struma consumption, renal calculus and scirrhus were highly prescribed by the doctors of early $19^{\text {th }}$ century (Connell, 2010) ${ }^{[17]}$.

\subsection{Cultural Assets - Centers of Care}

Many records of health tourism practices exhibits that sometimes not only the physical attractions but also the cultural assets, authentic and unique to certain locations help in driving health tourism from long time back. Thousands year old healing practice of Ayurveda, Traditional Chinese Medicine of China, Unani Medical Care System of Medieval Islamic Period and Modern Medicines of Western countries had cured many health seekers regardless of their countries of origin. The Renaissance and Post Renaissance Period of the $14^{\text {th }}$ to $19^{\text {th }}$ Century highlight the rebirth of Modern School of Medicine in Europe and England attracted wealthiest patients from every corner of the world. During $20^{\text {th }}$ century, USA and Europe were emerged as the centres of contemporary healthcare system. It has laid the foundation of medical tourism, a specific form of health tourism, which includes more invasive high-risk procedures. Ayurvedic Medicine, an indigenous Indian medical system is one of the world's oldest medical systems. It originated in India more than 5000 years ago and remains one of the country's traditional healthcare systems. The term 'Ayurveda' combines the Sanskrit words ayur (life) and veda (science). Its concept about health and diseases promote the use of herbal compounds, special diets and other unique health practices. The methods used to find this knowledge of herbs, foods, aromas, gems, colours, yoga, mantras, life style and surgery are fascinating and varied. It is said the sages, physicians and surgeons of the contemporary time were received their training of Ayurveda through direct cognition during meditation and divine revelation. Being its roots in Vedas especially 'Atharvaveda' and 'Rik Veda's, there were two schools of Ayurveda at the time of Atreya, the school of physicians and the school of surgeons which transformed Ayurveda into a scientifically verifiable and classifiable medical system. Charak, writer of Charak Samhita represents the Atreya School of Physicians, discussing physiology, anatomy, pathogenesis, symptoms and signs of disease, methodology of diagnosis, treatment and prescription for patients, prevention and longevity. His followers believe that first cause of illness is the loss of faith in the divine causing internal illness while external influences include time of the day, the season and life style. Sushruta comes from the Dhanvantari School of Surgeons. His book Sushruta Samhita presents a detailed account of surgical equipment, classification of abscesses, burns, fractures and wounds, amputation, plastic surgery and anal or rectal surgery. Human anatomy is also discussed in details. Through research and testing these two schools dispelled, the doubts of the more practical and scientific minded, removing the aura of mystery that surrounded the Divine revelation. Consequently, Ayurveda grew in respect and became one of the widely used systems of healing in India. There are many historical records highlighting the existence of constant flow of medical travellers and medical students from China, Tibet, Middle East and Europe flocked to India either to seek or to learn the benefits of this healing method. Nalanda at Patna India, a famous Ayurvedic centre was the main university at the centre of Silk Road, an established trade route between Asia (China, Tibet etc.), the Middle East (Afghanistan, Persia etc.) and Europe (Rome, Greece etc.). On this route travellers first found the benefits of Ayurveda (Tirtha, 1998) ${ }^{[18]}$. Till date Kerala, a state of South India serves thousands of health seekers every year across the borders of nations and continents. Many early Islamic cultures established health care systems that also catered for foreigners regardless of race or religion. Some of the best known of the great hospitals in the middle ages were in Baghdad, Damascus and Cairo and in India as discussed below -

(1) Adudi Hospital, Baghdad: In the modern sense of the world Adudi Hospital is the first hospital, built by Harun - al - Rashid in Baghdad in the beginning of the ninth century (786 C.E.). The hospital was characterised by good staff and effecting caring facilities. It was not only looked after and cured patients regardless of race, religion and social background but also served as a focal point for the medical students who visited there from distant places (Smith, 1996) ${ }^{[19]}$.

(2) Nuri Hospital, Damascus: Nuri Hospital built in Damascus, one of the glories of Islam with its library and pharmacy served as one of the greatest medical centres in Syria for over four centuries (Hamarneh, 1968) [20]

(3) $\mathrm{Al}$ - Mansuri Hospital, Cairo: In 1248 C.E. Al - Mansuri Hospital was built in Cairo with a capacity of 8000 beds and many specialized wards including general medicine, surgery, fractures, fever, eye diseases. $\mathrm{Al}$ - Mansuri Hospital became major healthcare destination at that time as patient admission was performed regardless of race, colour or religion. Hospital was provided a mosque for Muslim patients and a chapel for Christians. There was no time limit for in - patient treatments and patient stayed until he/she fully recovered. On discharge, the patient was given clothes and pocket money also (Ghazal, 2007) ${ }^{[21]}$.

(4) Dar - u - Shifa, The Grand Hospital, Hyderabad: In C.E. 1595, Sultan Muhammad Qutub Shah IV, and founder of the city of Hyderabad built a hospital known as Dar - u - Shifa (The House of the Cure) on the 
banks of the Moosi River. Dar - $\mathrm{u}$ - Shifa had accommodation for 4000 patients and many physicians were appointed for the treatment of the patients. There were about fifty-two public rest houses, where travellers from outside and far off places could rest and relax. They were also well provided with food and other necessities of life till their departure (Jaggi, 2000) ${ }^{[22]}$.

Delhi was also one of the favourite destinations for medical travellers, where the early Muslim conquerors brought their Unani or Islamic system of Medicine with their physicians and enriched Delhi as a healthcare hub of the then contemporary period. During the time of Muhammad - bin - Tughlaq (C.E. 1325 1352), there were about 70 hospitals alone in Delhi where 1200 physicians were employed as state employees. The next ruler Feroz - Shah - Tughlaq also had equivalent interest in building hospitals for the sick and troubled, both for natives and strangers and Arab Physicians were appointed to superintend it (Jaggi, 2000) ${ }^{[22]}$.

The Renaissance and Post - Renaissance Period, which highlight the rebirth of many modern school of medicine in Europe and America, also witnessed the growth of contemporary form of niche health tourism i.e. medical tourism. During this time, USA and Europe have emerged as centres of modern healthcare world. Its high quality and expensive but trusted medical care facilities had started to attract many affluent rich from different parts of the globe. Patients started to visit these hospitals, where travel is intentionally linked to direct medical intervention irrespective to the interest of visit to the natural attractions of the surroundings. Connell (2010) ${ }^{[17]}$ defines such type of patient migration as medical tourism: "Where travel is intentionally linked to direct medical interventions, and outcomes are expected to be substantial and long term is quite new - satisfying the needs of a growing number of people, who can be both tourists and patients"

Harley Street in many respects laid the foundation of modern medical tourism flow. It began to thrive as a medical centre, especially after the Medical Society of London opened in Chandos Street in 1873 then the Royal Society of Medicine in Wimpole Street in 1912. Since the nineteenth century the number of doctors, hospitals and medical organisations in and around Harley Street has greatly increased mainly because of its connectivity to railway. Records show that there were around 20 doctors in 1860, 80 by 1900 and almost 200 by 1914. When the National Health Service was established in 1948, there were around 1,500 doctors (Harley Street Guide Book, 2017) ${ }^{[23]}$.

In the 1960s, significant technical breakthrough in the USA served affluent patients from around the globe, and by 1980s, renowned medical centres such as Mayo Clinic, Johns Hopkins Hospital and the Cleveland Clinic had developed many formal programmes such as interpreter assistance with visa, travel and luxury accommodation facilities to attract overseas patients. Till date every year, more than a million people from all 50 states and nearly 150 countries come to Mayo Clinic for care (Mayo Clinic Fact Sheet, 2017) ${ }^{[24]}$. Cleveland Clinic has started its Global Patient Service since 1974. Every year, it serves over 3,000 people from nearly 140 different countries (Cleveland Clinic, 2017) ${ }^{[25]}$.

In fact such kind of international movement of patients in search of cures and resolution of more serious conditions often by surgery or operation urges to bring more serious and compact term medical tourism and replaces the softer and broader word healthcare tourism. Healthcare tourism includes broader phenomena ranging from travel for cure from prayers and meditation to hospitalization and surgeries but medical tourism as a sub set of healthcare tourism, implies diagnosis, hospitalization and surgical operations to improve or restore health in long term in which leisure or physical attraction of the place is a side factor. When and where the term 'medical tourism' originated is unknown but it is widely accepted as an international phenomenon (of) for individuals travelling since the late 1990s, in which patients travel foreign countries. Selection of destination includes individual's preference varying from lower cost, rapid access to high quality specialized care in host countries. However, the rise of medical tourism in its contemporary form is the result of -

(1) regional disparity in healthcare delivery sector;

(2) globalization of healthcare services, exposure of advanced medical techniques and skills following post industrial economies equipped with revolutionary tools of information and communication;

(3) growing trend of consumerism and emergence of middle class with new needs and demand;

(4) increasing share of 'for profit' business with commercialization, corporatization and marketization of healthcare across societies.

As a result, recent years have witnessed a growing number of patients' migration abroad for medical care. An estimated 7.5 million Americans have travelled abroad for medical care in 2011 (Keckley, 2008) ${ }^{[26]}$. More than 46000 Canadians sought medical treatment outside of Canada in 2011 (Esmail, 2012) ${ }^{[27]}$. In 2010, the annual number of travellers leaving the UK for health care abroad was more than 60, 000 (National Statistics, 2011) ${ }^{[28]}$. Every year more than 50000 patients cross border from Bangladesh to avail medical treatment (Cortez, 2008) [29]. Thailand had treated 1.2 million inbound medical tourists in 2006 (Keckley, 2008) ${ }^{[26]}$. It is estimated that in India among total foreign tourist arrivals, about $3 \%$ were medical tourists in 2012 (Indian Tourism Statistics, $2012)^{[30]}$. As many as 25,000 people from UK have travelled to Hungary for dental care. Tunisia claims that about 250, 000 foreign patients visited here in $2009-10$ (Connell, 2010) ${ }^{[17]}$. 


\section{MEDICAL TOURISM - MODERN APPROACH}

Medical tourism is an act of travelling outside far from the place of residence with intent of accessing the opportunities of better medical care (Rai, Chakrabarty and Sarkar, 2014) ${ }^{[31]}$. However, it is usually curative in focuses opposed to more preventive scope of health and wellness tourism (Hall, 2013) ${ }^{[32]}$. Hunter see it as a contemporary form of an ancient social practice of health tourism where people for thousands of years have travelled to seek cures while on holiday through relaxation, exercise or visits to spas. However, it includes more invasive high-risk procedures than health tourism (Hunter, 2007) ${ }^{[1]}$.

As the seriousness of medical situation increases, the recreational aspects of tourism have diminishing importance here (Horowitz and Rosenweig, 2007) ${ }^{[33]}$. Therefore, medical tourism undoubtedly a global, economic and political phenomenon, which implies diagnosis, hospitalization and surgical operations to improve or restore health in long term often, considered as the sub-set of health tourism in which leisure or physical attractions of destination is a side factor while making decisions of treatment abroad. Specialization has transformed it into an emerging niche market of medical tourism which is further characterised by an industry approach (Tata, 2009) ${ }^{[2]}$, driven by the market forces of demand and supply as shown in Figure.1.Previously it was limited to elites from developing countries to developed ones, when health care was not satisfactory at home. However, the scenario is changing towards developing countries and globalization and commoditisation of health services have led to an organized medical tourism for fee-paying patients, regardless of their country of origin. They buy health services overseas using new information sources, new mediators to connect them to providers, and inexpensive air travel to reach their medical destination (Pocock and Phua, 2011) ${ }^{[34]}$. According to Gautam $(2008)^{[4]}$ :

"medical tourism can be defined as provision of 'cost effective' private medical care in collaboration with the tourism industry for patients needing surgical and other forms of specialized treatment....patients going to another country for either urgent or elective medical procedures could be defined as medical tourists". Bookman and Bookman (2007) ${ }^{[35]}$ identifies medical tourism as travel with the aim of improving one's health, an economic activity that entails trade in services and represents the splicing of at least two sectors medicine and tourism and everyone coming from everywhere, is shopping for doctor in the international health services market and as a result, enjoys a cost savings over the alternative at home". Bies and Zacharia (2007) ${ }^{[36]}$ consider medical tourism as the outsourcing of medical services, primarily expensive surgeries, to low-cost countries, such as India and Thailand."

In fact in $21^{\text {st }}$ century, an act of medical tourism can be defined as the latest response against the face of the widening gap that exists on global scale while availing medical opportunities (Rai, Chakrabarty and Sarkar, 2014) ${ }^{[31]}$. On the demand side regional disparity in accessing medical care have spurred the migration of patients while on supply side several countries or service providers have dramatically improved the quality of care they can offer through international accreditation equipped with cheap and skilled human resources to tap international market of migrating patients as a major source of foreign exchange. As stated before, when and where the term 'medical tourism' originated is unknown, but it is believed as a popular consumer - driven internet search term. As we know internet has become first step in making decisions, people are increasingly turning to the internet for health related information. To find information about medical treatment abroad, consumers most preferably like to type 'medical tourism' (Munro, 2012) ${ }^{[37]}$ which gives back millions of result in few seconds as shown in Figure 2.

\section{MEDICAL TOURISM - SALIENT FEATURES}

The foregoing discussion brings out the following salient features of modern medical tourism -

1) Medical tourism is curative in nature rather preventive.

2) It focuses more on specialized medical services, supposed to be received at modern medical facility or hospital.

3) It is also not an impulsive activity. However, it is believed that much of the emergence of this $\$ 300$ billion medical tourism industry is credited primarily to internet searches, word of mouth and referrals. Therefore, successful treatments and satisfactory service performance are major contributing factors for the growth and development of this business.

4) As a response against the dire need of medical care, medical tourism is not a seasonal activity. This attribute encourages many service providers to adopt it as a main business to overcome the seasonality of location specific tourist centres.

5) Another important of feature of medical tourism is its high tourist spending and long duration of stay as compared to the conventional corporate or holiday travel. The average stay of medical tourist ranges between few weeks to few months depending upon the procedures and nature of the treatments. For example, procedure as complex as open - heart surgery including post - operative care involve a stay for at least two weeks while procedures related to fertility care involve duration of at least eight to eleven months. 


\section{CONCLUSION}

Regional disparity in healthcare sector has recently reshaped the ancient practice of health tourism into its contemporary form of medical tourism. Triggered by the global demand, medical tourism has become a truly global phenomenon where patients cross borders to seek better care than what they find in their country of origin.

Figure1 Medical Tourism - a subset of healthcare tourism

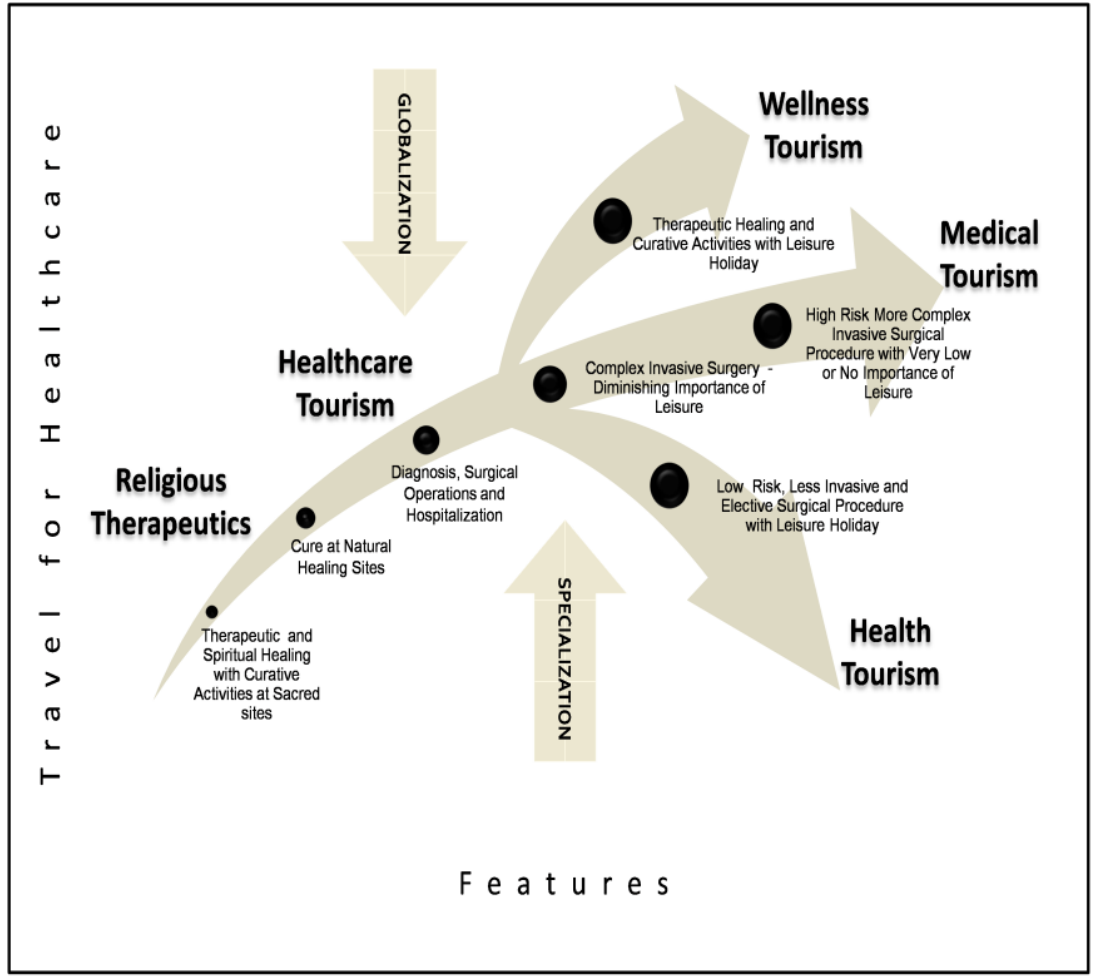

Figure 2 Google search result page for "Medical tourism" accessed on 03.04.2017

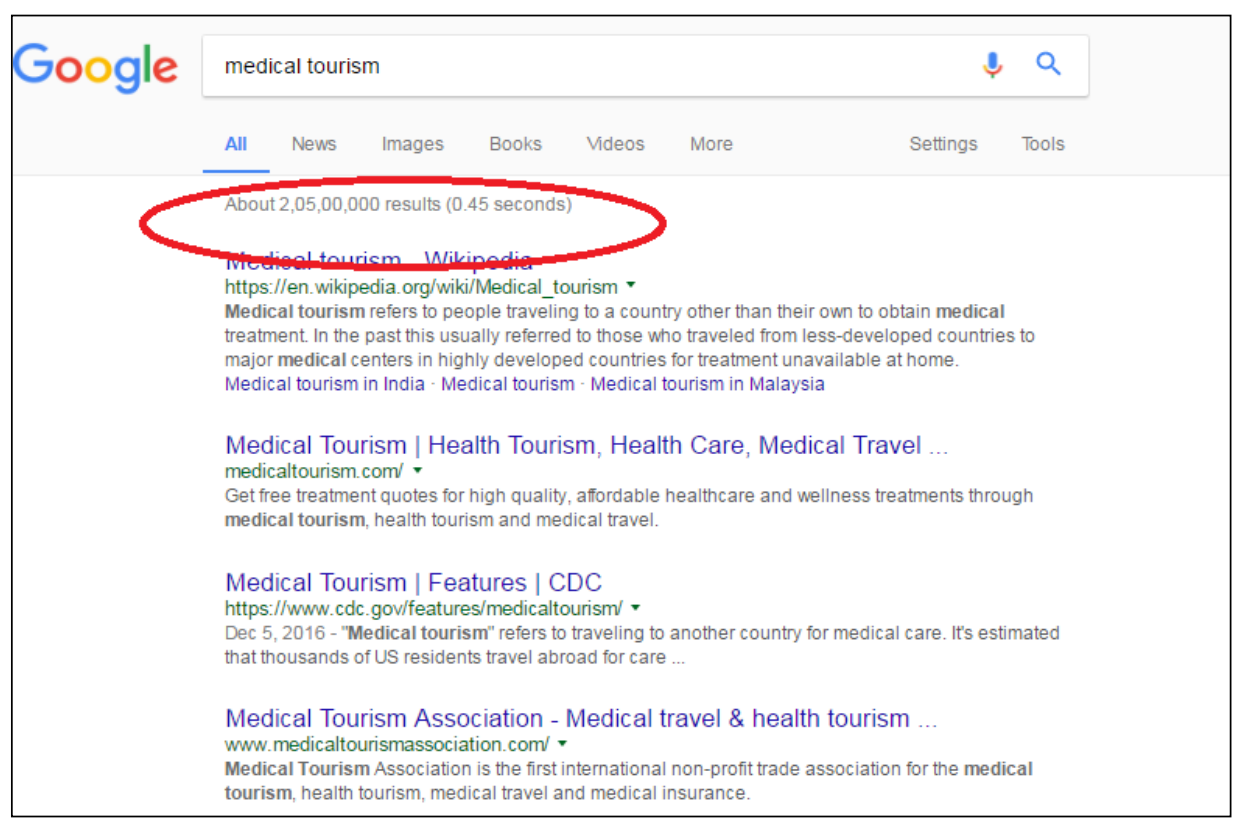




\section{REFERENCES}

[1] Hunter, W C. Medical Tourism: A Global Niche, International Journal of Tourism Science 7, no. 1, 2007: 129 - 140. Ibid.

[2] Tata, S. Medical travel in Asia and the Pacific Challenges and Opportunities. Background Paper, Bangkok: United Nations Economic and Social Commission for Asia and the Pacific (ESCAP) 63rd Commission Session, 2009. Ibid.

[3] Fields, G P. Religious Therapeutics: Body and Health in Yoga, Ayurveda and Tantra. Albany, New York: State University of New York Press, 2001. Ibid.

[4] Gautam, V. Healthcare Tourism: Opportunities for India Mumbai. Mumbai: Avdhut Kumbhavdekar for Exim Bank of India and Quest Publication, 2008. Ibid.

[5] Jayne, W.A. The Healing Gods of Ancient Civilization. USA: Yale University Press, 1925. Ibid. Ibid. Ibid.

[6] Gopi, R. "Ayurveda Tourism and Masculinity in Contemporary Kerala." IOSR Journal of Humanities and Social Science 19, no. 5, Ver IV (May 2014): 62 - 73.

[7] Zysk, K G. Ascetism and Healing in Ancient India: Medicine in the Buddhist Monastery. New York and Oxford: Oxford University Press, 1991. Ibid. Ibid.

[8] Chakravorty R, Ray K. Healing and Healers Inscribed: Epigraphic Bearing on Healing Houses in Early India. Occassional Paper, Kolkata: Institute of Development Studies Kolkata, 2011. Ibid.

[9] Wikipedia: The Free Encyclopedia - Vichy. 2017. http://en.wikipedia.org/wiki/Vichy (accessed February 20, 2017).

[10] Wikipedia: The Free Encyclopedia - Bath. 2017. http://en.wikipedia.org/wiki/Bath,_Somerset (accessed February 20, 2017).

[11] Wikipedia: The Free Encyclopedia - Aachen. 2017. http://en.wikipedia.org/wiki/Aachen (accessed February 20, 2017).

[12] Wikipedia: The Free Encyclopedia - Wiesbaden . 2017. http://en.wikipedia.org/wiki/Wiesbaden (accessed February 20, 2017).

[13] Seki, A, and Brooke E H. Ryoken: Japan's Finest Spas and Inns. Tokyo: Tuttle Publications, 2007. Ibid. Ibid. Ibid. Ibid. Ibid.

[14] Wikipedia: The Free Encyclopedia - Beppu Onsen. 2017. http://en.wikipedia.org/wiki/Beppu_Onsen (accessed February 20, 2017)

[15] Wikipedia: The Free Encyclopedia - Yunogo Onsen. http://en.wikipedia.org/wiki/Yunogo_Onsen (accessed february 20, 2017).

[16] Wikipedia: The Free Encyclopedia - Onsen. 2017. http://en.wikipedia.org/wiki/Onsen (accessed Frbruary 15, 2017).

[17] Connell, J. Medical Tourism. United Kingdom: Cab International, 2010. Ibid. Ibid.

[18] Tirtha, S. S. The Ayurveda Encyclopedia: Natural Secrets to Healing, Prevention and Longevity. 5th Ed. (2005). Edited by Chndhok J. K.,Sandhu S. Unyal R.C. USA: Ayurveda Holistic Centre, 1998.

[19] Smith, E S. Medicine. Vol. III, in Encyclopedia of History of Arabic Science: Technology, Alchemy and Life Science, by R Rashed, edited by R Rashed, 903 - 962. New York: Routledge, 1996.

[20] Hamarneh, S. Medical Education and Practice in Medieval Islam. Vol. 673, in The History of Medical Education: An International Symposium, by C D O'Malley, edited by C D O'Malley, 39 - 72. USA: UCLA Dept of Medical History, School of Medicine, 1968.

[21] Ghazal, S K A. "The Origin of Bimaristan (Hospitals) in Islamic Medical History." Foundation for Science, Technology and Civilisation. Edited by M E Gomti. Foundation for Science, Technology and Civilisation. April 2007. http://www.fstc.co.uk (accessed September 25, 2014).

[22] Jaggi, O P. "Hospitals in India." In Medicine in India: Modern Period, by D P Chattopadhyay, 70 - 74 . New Delhi: PHISPC, 2000. Ibid.

[23] Harley Street Guide Book. 2005. http://www.harleystreetguide.co.uk/about/history/ (accessed February 11, 2017)

[24] Mayo Foundation for Medical Education and Research. 1998 - 2017 . http://www.mayoclinic.org/about-mayo-clinic/facts-statistics (accessed April 15, 2017).

[25] Cleveland Clinic. 1995. http://my.clevelandclinic.org/patients-visitors/international/why-choose-us (accessed October 15, 2014).

[26] Keckley, P H. Medical Tourism: Consumers in Search of Value . Survey of Health Care Consumers, Washington: Deloitte Centre for Health Solutions, 2008.

[27] Esmail, N. Leaving Canada for Medical Care 2011 . Forum, Fraser Forum Institute, 2012 (July August), $18-19$.

[28] National Statistics NHS Referral to Treatment (RTT) Waiting Times Statistics for England . Annual Report, Department of Health, Department of Health, UK, 2011. 
[29] Cortez, N. "Patients Without Borders: The Emerging Global Market for Patients and the Evolution of Modern Heath care.” Indiana Law Journal 83, no. 1 (2008): 71 - 132.Ibid.

[30] India Tourism Statistics . Annual Report, Market Research Division, Delhi: Ministry of Tourism, Govt. of India, 2012. Ibid.

[31] Rai, A, P Chakrabarty, and A Sarkar. "Regional Imbalance in Medical Opportunities: Bridging the Gap by Medical Tourism.” Thematics Journal of Geography 2.0, no. 4 (2013): 176 - 182.

[32] Hall, C M. "Medical and Health Tourism: the development and implications of medical mobility." In Medical Tourism: The Ethics, Regulation and Marketing of Health Mobility, by C M Hall, 1 - 28. Abingon, Oxon: Routledge, 2013.

[33] Horowitz, M D, and A J Rosensweig. "Medical Tourism- Health Care in the Global Economy." The Physician Executive 30 , no. 6 (November-December 2007): 24-30. Ibid.

[34] Pocock, N S, and Phua K H. "Medical tourism and policy implications for health systems: a conceptual framework from a comparative study of Thailand, Singapore and Malaysia." Globalization and Health 7, no. $12(2011)$

[35] Bookman, M Z, and Bookman K R. Medical Tourism in Developing Countries. New York: Palgrave Macmillan, 2007.

[36] Bies, W, and L Zacharia. "Medical Tourism: Outsourcing Surgery." Mathmatical and Computer Modelling 46 (2007): 1144-1159.Ibid.

[37] Munro, J W. "Best Practices in Medical Tourism - What is Medical Tourism." MTQUA, Medical Travel Quality Alliance. 2012. www.mtqua.org (accessed October 5, 2014). 